\title{
TiB Nanowhisker Reinforced Titanium Matrix Composite with Improved Hardness for Biomedical Applications
}

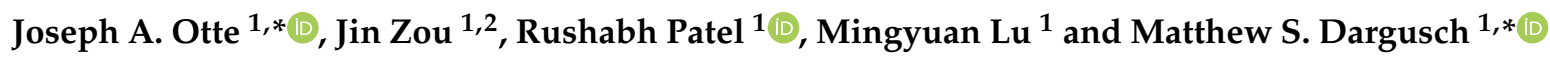 \\ 1 School of Mechanical and Mining Engineering, The University of Queensland, Brisbane 4072, Australia; \\ j.zou@uq.edu.au (J.Z.); r.patel@uq.edu.au (R.P.); m.lu1@uq.edu.au (M.L.) \\ 2 Centre for Microscopy and Microanalysis, The University of Queensland, Brisbane 4072, Australia \\ * Correspondence: joseph.otte@uqconnect.edu.au (J.A.O.); m.dargusch@uq.edu.au (M.S.D.); \\ Tel.: +61-4-359-14697 (J.A.O.); +61-7-334-69225 (M.S.D.)
}

Received: 4 November 2020; Accepted: 8 December 2020; Published: 10 December 2020

\begin{abstract}
Titanium and its alloys have been employed in the biomedical industry as implants and show promise for more broad applications because of their excellent mechanical properties and low density. However, high cost, poor wear properties, low hardness and associated side effects caused by leaching of alloy elements in some titanium alloys has been the bottleneck to their wide application. TiB reinforcement has shown promise as both a surface coating for Ti implants and also as a composite reinforcement phase. In this study, a low-cost TiB-reinforced alpha titanium matrix composite (TMC) is developed. The composite microstructure includes ultrahigh aspect ratio TiB nanowhiskers with a length up to $23 \mu \mathrm{m}$ and aspect ratio of 400 and a low average Ti grain size. TiB nanowhiskers are formed in situ by the reaction between Ti and BN nanopowder. The TMC exhibited hardness of above 10.4 GPa, elastic modulus above $165 \mathrm{GPa}$ and hardness to Young's modulus ratio of 0.062 representing $304 \%, 170 \%$ and $180 \%$ increases in hardness, modulus and hardness to modulus ratio, respectively, when compared to commercially pure titanium. The TiB nanowhisker-reinforced TMC has good biocompatibility and shows excellent mechanical properties for biomedical implant applications.
\end{abstract}

Keywords: nano-composite; microstructure; nanoindentation; bone implants; powder metallurgy

\section{Introduction}

As our population ages the need for effective bone implants as treatments for arthritis and other joint-related pain is of growing importance [1,2]. Current projections indicate that in the United States replacement surgery for hips and knee arthroplasties will increase by over $600 \%$ to more than 4 million operations by 2030 [3]. Many of these surgeries arise due to failure of the original implant and need for a second replacement surgery which can lead to several associated health concerns. Pure titanium (CP-Ti) stands out as a good material for load-bearing joint replacements because of its strong specific properties, corrosion resistance and good biocompatibility [4,5]. However, poor wear resistance of Ti limits its usefulness as the removal of the surface of the implant over time not only contributes to the breakdown of the implant but can also lead to inflammation and related immune responses in the affected area [6]. Attempts to improve strength and wear resistance of Ti through alloying has introduced elements which are prone to leach out over time into the body, limiting their safe use and lifetime [7]. A Ti-based material that retains the aforementioned strengths in biocompatibility and corrosion performance with increased hardness and wear resistance will be a strong candidate as an implant material.

One possible avenue for improving the wear properties is by the surface treatment of $\mathrm{Ti}$, typically with a coating of hydroxyapatite, by methods such as dip coating, plasma spraying and 
electrochemical deposition [8-11] amongst others. Hydroxyapatite is a constituent of hard tissues and so interfaces well with the human body when implanted [12]. However, these coatings add an additional cost to the already expensive manufacture of $\mathrm{Ti}$ implants and in addition have low bond strength to $\mathrm{Ti}$ and are prone to peel off during long-term service [4]. With these facts, producing an uncoated Ti component with strong wear properties is desirable.

Titanium matrix composites (TMCs) have many of the desirable properties for bone implants, with significantly improved hardness and wear properties when compared to CP-Ti. By reinforcing with stiff and strong ceramic particles or fibres, Ti has shown significantly improved strength, hardness and wear resistance [13-19]. In addition, many of the most promising reinforcements $\left(\mathrm{Ti}_{\mathrm{x}} \mathrm{B}, \mathrm{TiC}\right.$ and $\mathrm{Ti}_{\mathrm{X}} \mathrm{N}$ ) can be manufactured 'in situ' meaning that the reinforcement phase is formed during processing (typically facilitated by a reaction at high temperature), which reduces overall process steps and leads to strong bonding at the reinforcement interface [20-22]. Among these materials TiB stands out, as it naturally forms a hexagonal whisker morphology which offers an improved strengthening effect when compared to particle reinforcement [23]. TiB is also thermodynamically stable for room temperature operations, leading to stable overall mechanical properties.

There are important concerns about the safety and biocompatibility of whisker reinforced composites for implant materials. Several studies have sought to investigate the cytotoxicity and osteointegration of cells on TiB composites. A 29 vol\% TiB whisker reinforced CP-Ti TMC has been tested for biocompatibility and has shown, amongst other results, to have a $\mathrm{H}$ index similar to CP-Ti and approximately a third of Ti-6Al-4V indicating that the TiB had no adverse effect on biocompatibility and is not cytotoxic [24]. Similarly, a TiB-TiN Ti6Al4V coating has been shown to have strong biocompatibility and good osteointegration with $15 \mathrm{wt} \% \mathrm{BN}$ addition [25]. Further, towards dental implant applications, human gingival fibroblasts and osteoblasts on a CP-Ti sample coated with a TiB whisker composite showed similar performance to CP-Ti only indicating their suitability as a biomaterial with up to $10 \mathrm{wt} \%$ B addition [26]. Subsequently, studies on the corrosion behaviour of $\mathrm{TiB}$ whisker reinforced composites have shown that TiB composites exhibit stronger passive film formation and reduced corrosion when compared to CP-Ti in simulated body fluids (Hank's solution $37^{\circ} \mathrm{C}$ ) [27]. This suggests that $\mathrm{TiB}$ reinforced composites will remain stable without significant corrosion, preventing leaching of harmful foreign elements. There is very little chance that TiB nanowhiskers will be released into the body. The strong bond between the Ti matrix and TiB produced by an in situ reaction has been shown to significantly reduce fibre pullout and improves the safety of these materials [28]. Further study is required in this area and 'in vivo' studies are recommended to identify any potential hazards of TiB nanowhisker-reinforced composites, particularly when subjected to long periods of articulating wear. However, these early studies show that TiB nanowhisker-reinforced TMCs have strong potential to be a safe, viable and long-lasting biomaterial for implant applications.

CP-Ti samples have found strong industrial application as biomedical implants particularly in low wear areas like the femoral stem [28]. However, there are two key problems that need to be addressed. Firstly, a high hardness and wear resistant material is required for high wear and articulating applications such as the femoral head [29]. Secondly, the complexity of coatings coupled with the risk of poor bonding at the surface increases the cost and can reduce the lifetime of coated implants, leading to expensive and dangerous replacement surgery [4]. TiB reinforced matrix composites are in a position to overcome these challenges as a single material can fill the role of a wide range of load bearing implants and with relatively low cost and long lifetime. However, there is a need to develop a thorough understanding of the manufacture of these composites and the optimization of the in situ reaction before they can find useful industrial application in the biomedical industry.

In this study, we demonstrate a cost-effective method to manufacture high aspect ratio TiB nanowhisker reinforced TMCs for load bearing biomedical applications, with mechanical properties investigated by nanoindentation. 


\section{Materials and Methods}

In this study, TMC samples were prepared by a process of powder mixing followed by cold compaction and vacuum sintering. CP-Ti gas atomized spherical powders $(0-45 \mu \mathrm{m})$ were combined with BN hexagonal nanopowders $(65-75 \mathrm{~nm})$. One batch of samples was produced with $5 \mathrm{vol} \% \mathrm{BN}$ and another with $10 \mathrm{vol} \%$ BN. Powders were then mixed, compacted and vacuum sintered using the same method as previously reported [15]. Samples were sintered at peak temperatures ranging from 1050 to $1200^{\circ} \mathrm{C}$ with the holding times ranging from 2 to $6 \mathrm{~h}$ to facilitate the in situ reaction between Ti and $\mathrm{BN}$ for the formation of TiB. The furnace heating and cooling rate was fixed at $2{ }^{\circ} \mathrm{C} / \mathrm{min}$ for all samples. In addition, to reduce the risk of chloride impurities and oxidation, samples were sintered on a bed of yttrium oxide and surrounded with blocks of sponge Ti.

The microstructural characteristics of the manufactured samples were analysed using scanning electron microscopy (SEM, Hitachi SU3500, Brisbane, Australia) and transmission electron microscopy (TEM, Hitachi HF5000, Brisbane, Australia). To prepare samples for SEM imaging, conventional metallographic polishing techniques were used with some SEM specimens etched in a modified Kroll's solution $\left(86 \% \mathrm{H}_{2} \mathrm{O}, 10 \% \mathrm{HNO}_{3}\right.$ and $\left.4 \% \mathrm{HF}\right)$ for $30 \mathrm{~s}$. TEM specimens were prepared by two methods. Firstly, bulk samples after sintering were deeply etched with the modified Kroll's solution for 3 min before being ultrasonicated in ethanol to extract and disperse nanowhiskers in solution. This solution was then dripped onto standard carbon grids, so isolated nanowhiskers could be investigated and measured. Secondly, TEM lamellae were prepared from bulk sintered samples with a FEI Scios Dual Beam FIB using a standard Ga ion beam cut and lift out technique [30]. Sample phases were characterized using a Rigaku SmartLab X-Ray diffractometer (XRD) with a $9 \mathrm{~kW}$ rotating $\mathrm{Cu}$ anode source. $45 \mathrm{kV}$ and $200 \mathrm{~mA}$ were used to generate a $300 \mu \mathrm{m}$ beam with data recorded by continuous scan from $20-80^{\circ} 2 \theta$ angle in $0.02^{\circ}$ increments.

Mechanical properties of the manufactured samples were investigated by nanoindentation tests using a Hysitron Triboindenter with a Berkovich probe. Nanoindentation was chosen in favour of tensile tests because local property measurement facilitates the study of TiB size and microstructural effects, without being affected by other sample variables present in sintered samples, such as porosity. A $12 \mathrm{mN}$ load was chosen as tests conducted with this load in a previous work gave mechanical properties on CP-Ti comparable to that obtained from tensile tests [15]. Oliver-Pharr (OP) analysis was used to determine hardness $(\mathrm{H})$ and reduced elastic modulus $\left(E_{r}\right)$ from the load $(\mathrm{P})$ - depth $(\mathrm{h})$ curve. Elastic modulus $(E)$ was then calculated using Equation (1) as shown below, where $v_{i}$ and $E_{i}$ are the Poisson's ratio and elastic modulus of the diamond indenter $(0.07$ and $1140 \mathrm{GPa})$ and $v$ and $E$ are the samples Poisson's ratio and elastic modulus. Details of OP analysis method can be found in [31]. Samples were tested with at least 100 indents in a $10 \times 10$ matrix with $10 \mu \mathrm{m}$ spacing to ensure the result was not affected by the plastic zone of the adjacent indents.

$$
\frac{1}{E_{r}}=\frac{1-v^{2}}{E}+\frac{1-v_{i}^{2}}{E_{i}}
$$

\section{Results and Discussion}

\subsection{Powder Mixing}

Powder mixing plays an important role in the manufacture of composite materials [32]. Firstly, proper mixing ensures a uniform distribution of the reinforcement phase in the product part, leading to more uniform mechanical properties. Secondly, when considering in situ processes, well-mixed powders have a higher and more consistent contact area between the two powders which will undergo the in situ reaction. Strong interfacial contact between the reacting particles reduces the risk of any particles remaining unreacted after processing and increases the nucleation rate, acting to refine the microstructure [33]. Figure 1 shows the powders before and after mixing, in which Figure 1a shows the BN nanoparticles as purchased from Nanografi. The BN particles have a plate-like 
morphology, up to $100 \mathrm{~nm}$ in diameter and with a typical thickness of $<10 \mathrm{~nm}$. Figure $1 \mathrm{~b}$ is a low magnification SEM image showing the spherical CP-Ti powders used in this work. Figure 1c,d are secondary electron (SE) and back-scatter electron (BSE) images, respectively, showing the powders after mixing for $4 \mathrm{~h}$ in a low energy Turbula shaker mixer with a 3:1 ratio of steel balls [15]. Figure 1c shows the fine BN powders are well distributed across the surface of the CP-Ti and similarly in Figure 1d, where dark patches are indicative of BN. It is clear from this image that BN has been distributed around the surface of CP-Ti particles. Figure 1c also shows some BN plates embedded into the Ti particle which will further promote their in situ reaction. In addition, it is clear that BN nanoparticle agglomerates like those shown in Figure 1a were largely broken up during mixing. Therefore, this mixing process has been effective to distribute BN.

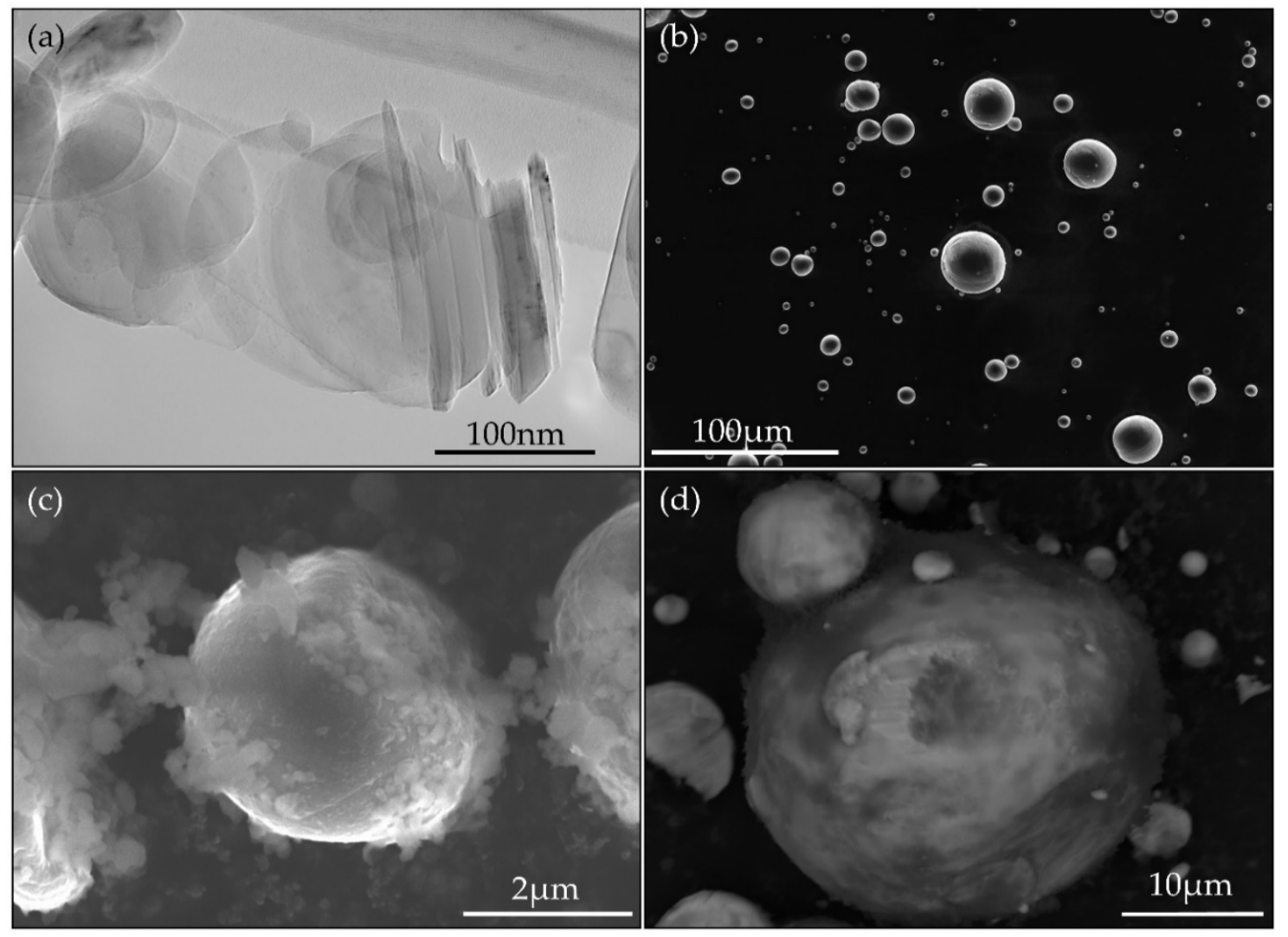

Figure 1. TEM and SEM images of powders before and after mixing: (a) TEM image of boron nitride powder as received; (b) SEM image of CP-Ti powder as received; (c) secondary electron SEM image of powders after mixing; (d) back-scatter electron image of powders after mixing.

\subsection{Microstructure}

Figure $2 \mathrm{a}$ is a low magnification TEM image showing a nanowhisker extracted from a sample sintered at $1050{ }^{\circ} \mathrm{C}$ for $6 \mathrm{~h}$ with an inset high magnification image. This particular nanowhisker had a length and diameter of approximately $18.4 \mu \mathrm{m}$ and $47 \mathrm{~nm}$, respectively, which was measured along with several others from each set of sintering conditions to obtain the average aspect ratios of the nanowhiskers in each sample. As shown in our previous study these whiskers are TiB [15]. However, to analyse the effect of BN concentration on the chemical nature of the samples, XRD was conducted on a CP-Ti $+10 \% \mathrm{BN}$ powder sample and then the same powder after sintering at $1150{ }^{\circ} \mathrm{C}$ for $6 \mathrm{~h}$ with subsequent surface etching (Figure 2b). Each peak in the powder sample was indexed by either hexagonal BN or hexagonal $\alpha$ Ti. The XRD peaks in the sintered sample were all indexed by orthogonally-structured TiB and $\alpha \mathrm{Ti}$ (Figure $2 \mathrm{~b}$ ), leading to two key findings. Firstly, no BN was detected in the samples after sintering, either in XRD or visible in SEM and TEM imaging, showing that 
all BN has undergone the in situ reaction. Secondly, TiN was also not detected in XRD or SEM and TEM imaging. TiN is regularly present as a product of the reaction between $\mathrm{Ti}$ and $\mathrm{BN}$ in rapid melting and solidification processes such as laser engineered net shaping (LENS) [25]. However, in slow heating and cooling solid-state processes, such as the furnace sintering employed in this work, no TiN is observed [34,35]. Nitrogen has a wide range of solubility in $\mathrm{CP}-\mathrm{Ti},>8 \mathrm{wt} \%$ at $1050{ }^{\circ} \mathrm{C}$ but approaching $<0.1 \mathrm{wt} \%$ at room temperature [36]. Furnace cooling $\left(2{ }^{\circ} \mathrm{C} / \mathrm{min}\right)$ allows the sample to achieve the low temperature equilibrium state with very low solute nitrogen, which was not detected by XRD or EDS in this work or previous studies [15]. The combination of the low solubility of nitrogen at room temperature, the achievement of room temperature equilibrium in slow cooling processes and the absence of detected TiN leads to the conclusion that the nitrogen from BN in this work is lost to the atmosphere during processing.
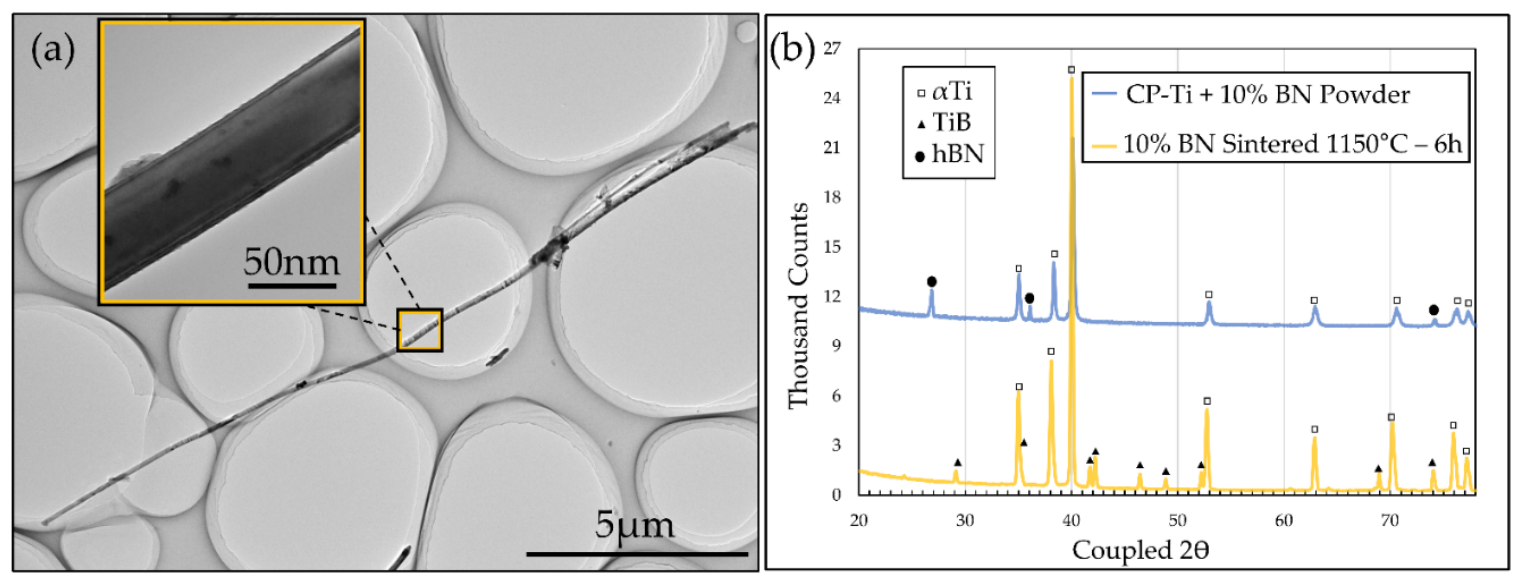

Figure 2. (a) TEM image showing a nanowhisker extracted from $10 \%$ BN sample after sintering at 1050 ${ }^{\circ} \mathrm{C}$ for $6 \mathrm{~h}$, with inset high magnification image for measuring whisker diameter; (b) XRD pattern of $10 \% \mathrm{BN}$ powder before sintering and after sintering at $1150{ }^{\circ} \mathrm{C}$ for $6 \mathrm{~h}$.

In order to study the effect of BN concentration SEM images were taken at similar magnification for each of the sintering conditions used. Figure 3 a shows a $5 \mathrm{vol} \% \mathrm{BN}$ TMC sintered at $1200{ }^{\circ} \mathrm{C}$ for $6 \mathrm{~h}$ and etched for $30 \mathrm{~s}$ to reveal details of the microstructure around grain boundaries. For comparison, Figure $3 \mathrm{~b}-\mathrm{d}$ show $10 \mathrm{vol} \% \mathrm{BN}$ TMCs sintered for $6 \mathrm{~h}$ at $1050{ }^{\circ} \mathrm{C}, 1150^{\circ} \mathrm{C}$ and $1200{ }^{\circ} \mathrm{C}$ respectively, before $30 \mathrm{~s}$ etching. Each microstructure shows Ti grains with nano and microwhiskers of TiB. In order to investigate the effect of reinforcement, two batches of TMC powder were prepared, one with $5 \mathrm{vol} \%$ $\mathrm{BN}$ and one with $10 \mathrm{vol} \% \mathrm{BN}$. The $5 \mathrm{vol} \% \mathrm{BN}$ sample sintered at $1200{ }^{\circ} \mathrm{C}$ includes mostly microwhiskers with average length of approximately $20 \mu \mathrm{m}$ and diameter of $1 \mu \mathrm{m}$ (see Figure 3a). Similarly, when the concentration of $\mathrm{BN}$ is doubled to $10 \mathrm{vol} \%$ with the same sintering conditions, TiB whiskers exhibit a similar structure with average length of approximately $18 \mu \mathrm{m}$ and diameter of $0.8 \mu \mathrm{m}$ (see Figure $3 \mathrm{~d}$ ). This comparison shows that up to $10 \mathrm{vol} \%$ of $\mathrm{BN}$, the fraction of $\mathrm{BN}$ has little effect of the formation and growth of TiB. 

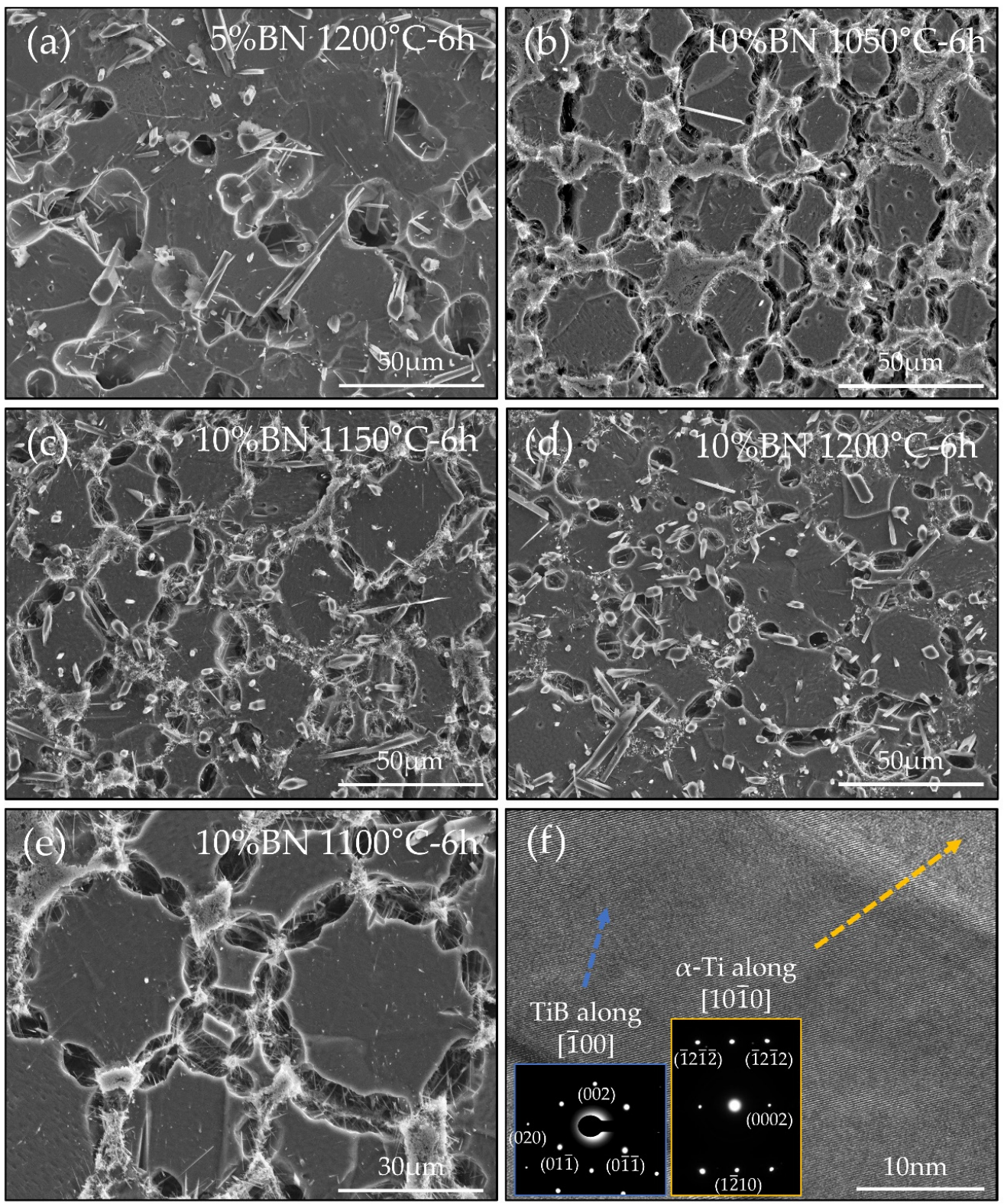

Figure 3. TEM and SEM images showing as-sintered TMC microstructure after etching: (a) SEM image of $5 \mathrm{vol} \% \mathrm{BN}$ TMC sintered at $1200{ }^{\circ} \mathrm{C}$ for $6 \mathrm{~h}$; (b) SEM image of $10 \mathrm{vol} \%$ BN TMC sintered at $1050{ }^{\circ} \mathrm{C}$ for $6 \mathrm{~h}$; (c) SEM image of $10 \mathrm{vol} \% \mathrm{BN}$ TMC sintered at $1150{ }^{\circ} \mathrm{C}$ for $6 \mathrm{~h}$; (d) SEM image of $10 \mathrm{vol} \% \mathrm{BN}$ TMC sintered at $1200{ }^{\circ} \mathrm{C}$ for $6 \mathrm{~h}$; (e) SEM image of $10 \mathrm{vol} \%$ BN TMC sintered at $1100{ }^{\circ} \mathrm{C}$ for $6 \mathrm{~h}$; (f) TEM image of FIB cut lamella from $10 \mathrm{vol} \% \mathrm{BN}$ TMC sintered at $1100{ }^{\circ} \mathrm{C}$ for $6 \mathrm{~h}$ with inset indexed selected area electron diffraction patterns of TiB and $\alpha$-Ti.

In addition to the effect of composition, the impact of processing temperature was investigated. Interestingly, when comparing Figure $3 \mathrm{~b}-\mathrm{d}$ a clear increase in the lateral dimension of TiB whiskers is observable. After sintering at $1050^{\circ} \mathrm{C}$, as in Figure $3 \mathrm{~b}$, there are very few TiB whiskers with a diameter greater than $100 \mathrm{~nm}$. Despite significant clustering of TiB, there is a propensity for TiB to remain as nanowhiskers after processing at $1050{ }^{\circ} \mathrm{C}$. TiB in the TMC sample sintered at $1050{ }^{\circ} \mathrm{C}$ for $6 \mathrm{~h}$ had an average diameter of $50 \mathrm{~nm}$ and length of $19 \mu \mathrm{m}$. By comparison, as temperature is increased to $1150{ }^{\circ} \mathrm{C}$ the number of $\mathrm{TiB}$ microwhiskers is increased, while still having significant amounts of TiB nanowhiskers (shown in Figure 3c). The TiB in the sample sintered at $1150{ }^{\circ} \mathrm{C}$ for $6 \mathrm{~h}$ has an average diameter of $65 \mathrm{~nm}$ and length of $23 \mu \mathrm{m}$. As temperature is further increased to $1200^{\circ} \mathrm{C}$, as shown in 
Figure $3 \mathrm{~d}$, few $\mathrm{TiB}$ nanowhiskers are observed, with the majority coarsened to microwhiskers. It is clear that between $1150{ }^{\circ} \mathrm{C}$ and $1200{ }^{\circ} \mathrm{C}$ the coarsening of TiB becomes active. This temperature range is consistent with previous studies [14,15], which were conducted on TMCs with lower boron additions indicating that the fraction of $\mathrm{TiB}$ present, up to $10 \mathrm{vol} \%$, in the sample has little effect on the critical coarsening temperature.

Figure 3e shows the microstructure of the TMCs produced by this method. After the removal of the Ti in the grain boundary a network structure of TiB interconnecting the Ti grains is observed. The use of low-energy mixing, fine BN and a solid-state sintering operation serves to preserve the structure. As TiB is formed in situ during sintering it grows from the surface of Ti particles into the adjacent particle acting as a grain boundary reinforcement. This microstructure is consistent with that observed in previous works [14,15,37-39]. The TiB present in the grain boundary also serves to restrict the grain growth of Ti grains as is commonly observed in slow heating/cooling processes like furnace sintering [37]. The average grain size in each $10 \mathrm{vol} \% \mathrm{BN}$ sample was approximately $7 \mu \mathrm{m}$. A primary detriment to the furnace sintering approach is the coarsening of the grain structure. Therefore, the formation of TMCs by this method, which restricts grain size to a minimum, is of strong benefit.

Figure $3 f$ and insets show a TEM image and selected area electron diffraction (SAED) patterns. Here, a section of a TiB nanowhisker with (011) atomic planes can be observed, indicating that the TiB nanowhisker is a single crystal. The provided SAED patterns provide evidence that the nanowhiskers are $\mathrm{TiB}$ with the typical orthorhombic structure, while $\mathrm{Ti}$ is present in the HCP structured alpha phase. As expected, no $\beta$-Ti was observed in the sample, only $\alpha$-Ti, due to the slow cooling rate $\left(2{ }^{\circ} \mathrm{C} / \mathrm{min}\right)$ allowing for the sample to achieve the equilibrium alpha phase. This thermodynamically stable microstructure is beneficial for long service bone implants as there is less risk of microstructural and therefore property changes over time [40].

\subsection{Mechanical Properties}

$\alpha$-Ti has excellent corrosion resistance and promotes rapid osteointegration because of a stable $\mathrm{TiO}_{2}$ film, where $\mathrm{OH}^{-}$ions present in this surface layer react with ions present in the bone structure like $\mathrm{Ca}^{2+}$ and $\mathrm{PO}_{4}{ }^{3-}$ to aid adhesion [7]. These properties make $\alpha$-Ti a strong candidate for bone implants. However, the poor fatigue performance and overall low strength have limited the application of CP-Ti and other $\alpha$-Ti alloys in load bearing implants [7]. A TMC with an $\alpha$-Ti matrix may offer improved strength and wear properties whilst retaining the corrosion resistance and biological interfacing benefits of $\alpha$-Ti.

Table 1 presents both results from nanoindentation tests along with mechanical property results from other works. When calculating average $\mathrm{E}$ and $\mathrm{H}$, values outside two standard deviations above the mean were rejected. This step was taken as surface damage and contamination can lead to large errors in results when performing nanoindentation [41]. Table 1 shows that our TMC samples exhibit high $\mathrm{E}$ and $\mathrm{H}$ values when compared to both $\mathrm{CP}-\mathrm{Ti}$ and other TMCs, even when a higher reinforcement fraction is used. Most notably, the $\mathrm{H} / \mathrm{E}$ ratio of samples is very high. The ratio of hardness to modulus is directly related to wear resistance and strain to failure [42]. The $10 \mathrm{vol} \% \mathrm{BN}$ sample sintered at $1150{ }^{\circ} \mathrm{C}$ for $6 \mathrm{~h}$ has the highest $\mathrm{H} / \mathrm{E}$ ratio of 0.062 , almost twice that of $\mathrm{CP}$-Ti. The ratio $\mathrm{H}^{3} / \mathrm{E}^{2}$, called yield pressure, is associated with yield strength $[42,43]$. The $10 \mathrm{vol} \% \mathrm{BN}$ sample sintered at $1150{ }^{\circ} \mathrm{C}$ for $6 \mathrm{~h}$ has the highest $\mathrm{H}^{3} / \mathrm{E}^{2}$ ratio $(0.041 \mathrm{GPa})$, which is an order of magnitude higher than that of CP-Ti and significantly higher than reported TMCs.

There are several contributing factors to the high performance of our TMCs, one of which is the previously described formation of a network microstructure with reduced grain size. As grain size is reduced, TiB grown in the grain boundary is sufficiently long to grow across the Ti grains, as can be seen in Figure 3. This leads to the improved local property measurement by nanoindentation throughout Ti grains, due to the strengthening effect of TiB. In addition to the increase in hardness and elastic modulus observed, there is an expected increase in bulk material strength as per the Hall-Petch relationship due 
to reduced grain size [44]. Also, network microstructures have previously been shown to improve both strength and ductility of TMCs $[15,21,38,45,46]$. Another key factor contributing to the performance of our TMCs is the high aspect ratio of TiB nanowhiskers, particularly in $10 \mathrm{vol} \% \mathrm{BN}$ samples. The aspect ratio of $\mathrm{TiB}$ in samples sintered at $1150{ }^{\circ} \mathrm{C}$ and lower is approximately 400 . It is well understood that increasing the aspect ratio of the reinforcement phase increases the strengthening efficiency of the reinforcement [23]. However, typically, when the fraction of reinforcement is increased, clustering of the secondary particles prior to the in situ reaction leads to coarsening of the reinforcement phase and, therefore, a decreasing of the strengthening efficiency [33]. In this work, BN fraction showed no effect on the size of $\mathrm{TiB}$, with high aspect ratio TiB nanowhiskers present when 10 vol\% $\mathrm{BN}$ was used. Figure $3 b-d$ show several fine TiB nanowhiskers grouped together which had not coarsened to microwhiskers. Previous studies have shown that there is a critical temperature for the coarsening of $\mathrm{TiB}$ between 1150 and $120{ }^{\circ} \mathrm{C}$ with low $\mathrm{TiB}$ fraction (less than $5 \mathrm{vol} \%$ ) [14,15]. It is clear from this study that $\mathrm{TiB}$ retains this critical temperature for coarsening when volume fraction is increased to $10 \mathrm{vol} \%$. Analysis of the formation reaction and coarsening of TiB in detail through in situ microscopy studies may provide necessary information to assist with the design of optimum manufacturing processes, both in solid and melt methods. The combination of increased volume fraction of TiB and maintaining ultrahigh aspect ratio nanowhiskers plays an important role in the enhanced properties of our TMCs.

Table 1. Summary of key results from nanoindentation tests, with results from other works for comparison.

\begin{tabular}{|c|c|c|c|c|c|c|}
\hline $\begin{array}{c}\text { Sample } \\
\text { Composition }\end{array}$ & Process Parameters & $\begin{array}{l}\text { Hardness/St. } \\
\text { Dev (GPa) }\end{array}$ & $\begin{array}{c}\text { Elastic } \\
\text { Modulus/St. } \\
\text { Dev (GPa) }\end{array}$ & $\mathrm{H} / \mathrm{E}$ & $\mathrm{H}^{3} / \mathrm{E}^{2}(\mathrm{GPa})$ & Reference \\
\hline $\mathrm{CP}-\mathrm{Ti}$ & $1200^{\circ} \mathrm{C}-6 \mathrm{~h}$ & $3.43 / 0.29$ & $94.4 / 2.3$ & 0.036 & 0.005 & This work \\
\hline $\mathrm{CP}-\mathrm{Ti}$ & SLM $120 \mathrm{~J} / \mathrm{mm}^{2}$ & 2.39 & 102 & 0.023 & 0.001 & [47] \\
\hline $\mathrm{Ti}+5 \mathrm{vol} \% \mathrm{BN}$ & $1200^{\circ} \mathrm{C}-6 \mathrm{~h}$ & $7.50 / 0.70$ & $147.7 / 15.4$ & 0.051 & 0.020 & This work \\
\hline $\mathrm{Ti}+10$ vol $\% \mathrm{BN}$ & $1050^{\circ} \mathrm{C}-6 \mathrm{~h}$ & $10.01 / 1.42$ & $170.7 / 21.0$ & 0.059 & 0.034 & This work \\
\hline $\mathrm{Ti}+10 \mathrm{vol} \% \mathrm{BN}$ & $1150^{\circ} \mathrm{C}-6 \mathrm{~h}$ & $10.48 / 1.23$ & $167.9 / 17.2$ & 0.062 & 0.041 & This work \\
\hline $\mathrm{Ti}+5$ vol $\% \mathrm{TiB}_{2}$ & SLM $120 \mathrm{~J} / \mathrm{mm}^{2}$ & 3.33 & 122 & 0.027 & 0.003 & [47] \\
\hline $\mathrm{Ti}+5$ vol $\% \mathrm{TiB}_{2}$ & $\operatorname{SPS} 1150^{\circ} \mathrm{C}-5 \mathrm{~min}$ & 4.1 & - & - & & \multirow{4}{*}{ [48] } \\
\hline $\mathrm{Ti}+5$ vol $\% \mathrm{TiB}_{2}$ & $\operatorname{SPS} 1250{ }^{\circ} \mathrm{C}-5 \mathrm{~min}$ & 4.3 & - & - & & \\
\hline $\mathrm{Ti}+25$ vol $\% \mathrm{TiB}_{2}$ & $\operatorname{SPS} 1150{ }^{\circ} \mathrm{C}-5 \mathrm{~min}$ & 7.1 & - & - & & \\
\hline $\mathrm{Ti}+25$ vol $\% \mathrm{TiB}_{2}$ & $\operatorname{SPS} 1250^{\circ} \mathrm{C}-5 \mathrm{~min}$ & 10.1 & - & - & & \\
\hline $\mathrm{Ti}+24 \mathrm{vol} \% \mathrm{TiB}$ & SPS $1100^{\circ} \mathrm{C}-5 \mathrm{~min}$ & $8.2^{1}$ & 162.6 & 0.050 & 0.021 & \multirow{3}{*}{ [49] } \\
\hline $\mathrm{Ti}+38.5 \mathrm{vol} \% \mathrm{TiB}$ & $1200^{\circ} \mathrm{C}-5 \mathrm{~h}$ & $9.7^{1}$ & 190.5 & 0.051 & 0.025 & \\
\hline $\mathrm{Ti}+20.6$ vol $\% \mathrm{TiB}$ & $\begin{array}{l}\mathrm{HIP} 1200^{\circ} \mathrm{C}, 120 \\
\mathrm{MPa}-5 \mathrm{~h}\end{array}$ & $8.0^{1}$ & 169.5 & 0.047 & 0.018 & \\
\hline
\end{tabular}

${ }^{1}$ Originally reported as Vickers hardness, converted to GPa.

\section{Conclusions}

To summarize, a TiB nanowhisker-reinforced $\alpha$-Ti matrix TMC was produced using a method of low energy mixing, cold compaction and furnace sintering. This TMC demonstrated increased strength and wear performance, addressing the two key weaknesses presently facing the use of $\alpha$-Ti for biomedical implants. Overcoming these challenges is a critical improvement for the development of affordable long-lasting biomedical implants to reduce the number of replacement surgeries required. Analysis showed that $\mathrm{TiB}$ is present as nanowhiskers with high aspect ratio in samples sintered at 1150 ${ }^{\circ} \mathrm{C}$ or below with relatively high volume fraction, up to $10 \mathrm{vol} \% \mathrm{BN}$. TiB nanowhiskers were observed to coarsen only when the sintering temperature was increased to $1200{ }^{\circ} \mathrm{C}$, even in high volume fractions of $\mathrm{BN}$, shedding light on the in situ reaction process and how it can be manipulated to achieve a refined reinforcement phase. The combination of high aspect ratio TiB in high volume fraction, a fine grain $\alpha$-Ti 
matrix and a network microstructure led to an increase in hardness and reduced modulus of more than 300 and $170 \%$ respectively when compared to CP-Ti. By improving these key properties while retaining the strong osteointegration and corrosion resistance of an $\alpha$-Ti matrix these TMCs are a strong candidate for the future of long-lasting load bearing implants. The TMCs produced in this work progress towards addressing the current challenges facing the biomedical implant industry by providing insight into: TiB reinforced TMCs, the in situ reactions at play and their optimized manufacture. Materials such as these will be vital to the next generation of high-performance load-bearing biomaterials.

Author Contributions: Conceptualization: J.A.O., M.S.D. and J.Z.; methodology: J.A.O. and M.S.D.; software: J.A.O. and R.P.; validation: J.A.O. and R.P.; formal analysis: J.A.O. and R.P.; investigation: J.A.O. and R.P.; resources: M.S.D., M.L. and J.Z.; data curation: J.A.O. and R.P.; writing-original draft preparation: J.A.O.; writing-review and editing: J.A.O., M.S.D. and J.Z.; visualization: J.A.O.; supervision: M.S.D., M.L. and J.Z.; project administration: J.A.O., M.S.D.; funding acquisition: M.S.D. All authors have read and agreed to the published version of the manuscript.

Funding: This research was funded by the University of Queensland's Centre for Advanced Materials Processing and Manufacturing (AMPAM) by the ARC research hub IH150100024.

Acknowledgments: The authors acknowledge the facilities, and the scientific and technical assistance, of the Microscopy Australia Facility at the Centre for Microscopy and Microanalysis, The University of Queensland.

Conflicts of Interest: The authors declare no conflict of interest.

\section{References}

1. Geetha, M.; Singh, A.K.; Asokamani, R.; Gogia, A.K. Ti based biomaterials, the ultimate choice for orthopaedic implants-A review. Prog. Mater. Sci. 2009, 54, 397-425. [CrossRef]

2. Long, M.; Rack, H.J. Titanium alloys in total joint replacement-A materials science perspective. Biomaterials 1998, 19, 1621-1639. [CrossRef]

3. Kurtz, S.; Ong, K.; Lau, E.; Mowat, F.; Halpern, M. Projections of primary and revision hip and knee arthroplasty in the United States from 2005 to 2030. J. Bone Jt. Surg. Am. Vol. 2007, 89, 780-785. [CrossRef]

4. Zhang, L.-C.; Chen, L.-Y. A Review on Biomedical Titanium Alloys: Recent Progress and Prospect. Adv. Eng. Mater. 2019, 21, 1801215. [CrossRef]

5. Chen, Y.; Frith, J.E.; Dehghan-Manshadi, A.; Attar, H.; Kent, D.; Soro, N.D.M.; Bermingham, M.J.; Dargusch, M.S. Mechanical properties and biocompatibility of porous titanium scaffolds for bone tissue engineering. J. Mech. Behav. Biomed. Mater. 2017, 75, 169-174. [CrossRef]

6. Kurtz, S.M.; Ong, K.L.; Schmier, J.; Mowat, F.; Saleh, K.; Dybvik, E.; Karrholm, J.; Garellick, G.; Havelin, L.I.; Furnes, O.; et al. Future clinical and economic impact of revision total hip and knee arthroplasty. J. Bone Jt. Surg. Am. Vol. 2007, 89A, 144-151. [CrossRef]

7. Mitragotri, S.; Lahann, J. Physical approaches to biomaterial design. Nat. Mater. 2009, 8, 15-23. [CrossRef]

8. Besra, L.; Liu, M. A review on fundamentals and applications of electrophoretic deposition (EPD). Prog. Mater. Sci. 2007, 52, 1-61. [CrossRef]

9. Boyd, A.R.; Rutledge, L.; Randolph, L.D.; Meenan, B.J. Strontium-substituted hydroxyapatite coatings deposited via a co-deposition sputter technique. Mater. Sci. Eng. C Mater. Biol. Appl. 2015, 46, 290-300. [CrossRef]

10. Liu, X.Y.; Ding, C.X.; Wang, Z.Y. Apatite formed on the surface of plasma-sprayed wollastonite coating immersed in simulated body fluid. Biomaterials 2001, 22, 2007-2012. [CrossRef]

11. Paital, S.R.; Dahotre, N.B. Calcium phosphate coatings for bio-implant applications: Materials, performance factors, and methodologies. Mater. Sci. Eng. R Rep. 2009, 66, 1-70. [CrossRef]

12. Egbo, M.K. A fundamental review on composite materials and some of their applications in biomedical engineering. J. King Saud Univ. Eng. Sci. 2020. [CrossRef]

13. Feng, H.; Zhou, Y.; Jia, D.; Meng, Q. Microstructure and mechanical properties of in situ TiB reinforced titanium matrix composites based on Ti-FeMo-B prepared by spark plasma sintering. Compos. Sci. Technol. 2004, 64, 2495-2500. [CrossRef]

14. Huang, L.; Qian, M.; Liu, Z.; Nguyen, V.T.; Yang, L.; Wang, L.; Zou, J. In situ preparation of TiB nanowires for high-performance Ti metal matrix nanocomposites. J. Alloy. Compd. 2018, 735, 2640-2645. [CrossRef] 
15. Otte, J.A.; Zou, J.; Huang, Y.; Dargusch, M.S. Ultrahigh Aspect Ratio TiB Nanowhisker-Reinforced Titanium Matrix Composites as Lightweight and Low-Cost Replacements for Superalloys. Acs Appl. Nano Mater. 2020, 3, 8208-8215. [CrossRef]

16. Ravi Chandran, K.; Panda, K.; Sahay, S. TiB Nanowhisker-reinforced Ti composites: Processing, properties, application prospects, and research needs. J. Miner. Met. Mater. Soc. (TMS) 2004, 56, 42-48. [CrossRef]

17. Saito, T.; Takamiya, H.; Furuta, T. Thermomechanical properties of $\mathrm{P} / \mathrm{M} \beta$ titanium metal matrix composite. Mater. Sci. Eng. A 1998, 243, 273-278. [CrossRef]

18. Tamirisakandala, S.; Bhat, R.B.; Ravi, V.A.; Miracle, D.B. Powder metallurgy Ti-6Al-4V-xB alloys: Processing, microstructure, and properties. JOM 2004, 56, 60-63. [CrossRef]

19. Tao, X.; Yao, Z.; Zhang, S. Reconstruction and refinement of TiB whiskers in titanium matrix composite after electron beam remelting. Mater. Lett. 2018, 225, 13-16. [CrossRef]

20. Kondoh, K. 16-Titanium metal matrix composites by powder metallurgy (PM) routes. In Titanium Powder Metallurgy; Qian, M., Froes, F.H., Eds.; Butterworth-Heinemann: Boston, MA, USA, 2015; pp. $277-297$. [CrossRef]

21. Lu, K. The Future of Metals. Science 2010, 328, 319. [CrossRef]

22. Zhang, C.J.; Kong, F.T.; Xiao, S.L.; Zhao, E.T.; Xu, L.J.; Chen, Y.Y. Evolution of microstructure and tensile properties of in situ titanium matrix composites with volume fraction of (TiB+TiC) reinforcements. Mater. Sci. Eng. A 2012, 548, 152-160. [CrossRef]

23. Koo, M.Y.; Park, J.S.; Park, M.K.; Kim, K.T.; Hong, S.H. Effect of aspect ratios of in situ formed TiB whiskers on the mechanical properties of TiBw/Ti-6Al-4V composites. Scr. Mater. 2012, 66, 487-490. [CrossRef]

24. Makau, F.M.; Morsi, K.; Gude, N.; Alvarez, R.; Sussman, M.; May-Newman, K. Viability of Titanium-Titanium Boride Composite as a Biomaterial. ISRN Biomater. 2013, 2013, 970535. [CrossRef]

25. Das, M.; Bhattacharya, K.; Dittrick, S.A.; Mandal, C.; Balla, V.K.; Sampath Kumar, T.S.; Bandyopadhyay, A.; Manna, I. In situ synthesized TiB-TiN reinforced Ti6Al4V alloy composite coatings: Microstructure, tribological and in-vitro biocompatibility. J. Mech. Behav. Biomed. Mater. 2014, 29, 259-271. [CrossRef]

26. Kaczmarek, M.; Jurczyk, M.U.; Miklaszewski, A.; Paszel-Jaworska, A.; Romaniuk, A.; Lipińska, N.; Żurawski, J.; Urbaniak, P.; Jurczyk, K. In vitro biocompatibility of titanium after plasma surface alloying with boron. Mater. Sci. Eng. C 2016, 69, 1240-1247. [CrossRef]

27. Chen, Y.; Zhang, J.; Dai, N.; Qin, P.; Attar, H.; Zhang, L.-C. Corrosion Behaviour of Selective Laser Melted Ti-TiB Biocomposite in Simulated Body Fluid. Electrochim. Acta 2017, 232, 89-97. [CrossRef]

28. Morsi, K. Review: Titanium-titanium boride composites. J. Mater. Sci. 2019, 54, 6753-6771. [CrossRef]

29. Ege, D.; Duru, İ.; Kamali, A.R.; Boccaccini, A.R. Nitride, Zirconia, Alumina, and Carbide Coatings on Ti6Al4V Femoral Heads: Effect of Deposition Techniques on Mechanical and Tribological Properties. Adv. Eng. Mater. 2017, 19, 1700177. [CrossRef]

30. Giannuzzi, L.A.; Stevie, F.A. A review of focused ion beam milling techniques for TEM specimen preparation. Micron 1999, 30, 197-204. [CrossRef]

31. Oliver, W.C.; Pharr, G.M. An improved technique for determining hardness and elastic modulus using load and displacement sensing indentation experiments. J. Mater. Res. 1992, 7, 1564-1583. [CrossRef]

32. Fang, Z.Z.; Paramore, J.D.; Sun, P.; Chandran, K.S.R.; Zhang, Y.; Xia, Y.; Cao, F.; Koopman, M.; Free, M. Powder metallurgy of titanium-Past, present, and future. Int. Mater. Rev. 2018, 63, 407-459. [CrossRef]

33. Brown, M.E.; Dollimore, D.; Galwey, A.K. Reactions in the Solid State. In Comprehensive Chemical Kinetics; Bamford, C.H., Tipper, C.F.H., Eds.; Elsevier: Amsterdam, The Netherlands, 1980; Volume 22.

34. Bhuiyan, M.M.H.; Li, L.H.; Wang, J.; Hodgson, P.; Chen, Y. Interfacial reactions between titanium and boron nitride nanotubes. Scr. Mater. 2017, 127, 108-112. [CrossRef]

35. Huang, L.; Qian, M.; Wang, L.; Chen, Z.-G.; Shi, Z.; Nguyen, V.; Zou, J. High-tensile-strength and ductile novel Ti-Fe-N-B alloys reinforced with TiB nanowires. Mater. Sci. Eng. A 2017, 708, 285-290. [CrossRef]

36. Wriedt, H.A.; Murray, J.L. The N-Ti (Nitrogen-Titanium) system. Bull. Alloy Phase Diagr. 1987, 8, 378-388. [CrossRef]

37. Huang, L.J.; Geng, L.; Peng, H.X. In situ (TiBw+TiCp)/Ti6Al4V composites with a network reinforcement distribution. Mater. Sci. Eng. A 2010, 527, 6723-6727. [CrossRef]

38. Huang, L.J.; Wang, S.; Dong, Y.S.; Zhang, Y.Z.; Pan, F.; Geng, L.; Peng, H.X. Tailoring a novel network reinforcement architecture exploiting superior tensile properties of in situ TiBw/Ti composites. Mater. Sci. Eng. A 2012, 545, 187-193. [CrossRef] 
39. Wang, S.; Huang, L.; An, Q.; Geng, L.; Liu, B. Dramatically enhanced impact toughness of two-scale laminate-network structured composites. Mater. Des. 2018, 140, 163-171. [CrossRef]

40. Oshida, Y. 5-Mechanical and Tribological Behaviors. In Bioscience and Bioengineering of Titanium Materials, 2nd ed.; Oshida, Y., Ed.; Elsevier: Oxford, UK, 2013; pp. 117-137. [CrossRef]

41. Dao, M.; Chollacoop, N.; Van Vliet, K.J.; Venkatesh, T.A.; Suresh, S. Computational modeling of the forward and reverse problems in instrumented sharp indentation. Acta Mater. 2001, 49, 3899-3918. [CrossRef]

42. Xu, J.; Wang, G.D.; Lu, X.; Liu, L.; Munroe, P.; Xie, Z.-H. Mechanical and corrosion-resistant properties of $\mathrm{Ti}-\mathrm{Nb}-\mathrm{Si}-\mathrm{N}$ nanocomposite films prepared by a double glow discharge plasma technique. Ceram. Int. 2014, 40, 8621-8630. [CrossRef]

43. Fornell, J.; Van Steenberge, N.; Varea, A.; Rossinyol, E.; Pellicer, E.; Suriñach, S.; Baró, M.D.; Sort, J. Enhanced mechanical properties and in vitro corrosion behavior of amorphous and devitrified Ti40Zr10Cu38Pd12 metallic glass. J. Mech. Behav. Biomed. Mater. 2011, 4, 1709-1717. [CrossRef]

44. Hall, E.O. The deformation and ageing of mild steel: Iii discussion of results. Proc. Phys. Soc. Sect. B 1951, 64, 747-753. [CrossRef]

45. Hu, Y.; Ning, F.; Wang, H.; Cong, W.; Zhao, B. Laser engineered net shaping of quasi-continuous network microstructural TiB reinforced titanium matrix bulk composites: Microstructure and wear performance. Opt. Laser Technol. 2018, 99, 174-183. [CrossRef]

46. Huang, L.J.; Geng, L.; Peng, H.X. Microstructurally inhomogeneous composites: Is a homogeneous reinforcement distribution optimal? Prog. Mater. Sci. 2015, 71, 93-168. [CrossRef]

47. Attar, H.; Ehtemam-Haghighi, S.; Kent, D.; Okulov, I.V.; Wendrock, H.; Bönisch, M.; Volegov, A.S.; Calin, M.; Eckert, J.; Dargusch, M.S. Nanoindentation and wear properties of Ti and Ti-TiB composite materials produced by selective laser melting. Mater. Sci. Eng. A 2017, 688, 20-26. [CrossRef]

48. Wei, S.; Zhang, Z.-H.; Wang, F.-C.; Shen, X.-B.; Cai, H.-N.; Lee, S.-K.; Wang, L. Effect of Ti content and sintering temperature on the microstructures and mechanical properties of TiB reinforced titanium composites synthesized by SPS process. Mater. Sci. Eng. A 2013, 560, 249-255. [CrossRef]

49. Selvakumar, M.; Chandrasekar, P.; Ravisankar, B.; Balaraju, J.; Mohanraj, M. Mechanical Properties of Titanium-Titanium Boride Composites Through Nanoindentation and Ultrasonic Techniques-An Evaluation Perspective. Powder Metall. Met. Ceram. 2015, 53, 557-565. [CrossRef]

Publisher's Note: MDPI stays neutral with regard to jurisdictional claims in published maps and institutional affiliations.

(C) 2020 by the authors. Licensee MDPI, Basel, Switzerland. This article is an open access article distributed under the terms and conditions of the Creative Commons Attribution (CC BY) license (http://creativecommons.org/licenses/by/4.0/). 